\title{
The impact of leadership styles on organizational culture in Mapsa company
}

\author{
Dariush Gholamzadeh $^{\mathrm{a}}$, Azadeh Tahvildar Khazaneh ${ }^{\mathrm{a}^{*}}$ and Manijeh Salimi Nabi ${ }^{\mathrm{b}}$
}

${ }^{a}$ Department of Management, Central Tehran Branch, Islamic Azad University, Tehran, Iran ${ }^{b}$ Department of Human Resources, Mapsa Company, Iran

\section{H R O N I C L E}

Article history:

Received March 22014

Accepted 29 July 2014

Available online

July 292014

Keywords:

Leadership Styles

Transformational Leadership

Transactional Leadership

Laissez-faire Leadership

Organizational Culture

\section{A B S T R A C T}

This paper examines the effect of leadership styles on organizational culture by testing a hypothesized model. A quantitative survey using questionnaire was conducted among 93 employees from diverse work units of Mapsa Company in October 2012. They filled out multifactor leadership questionnaire and the Denison organizational culture survey. Results of structural equation modeling (SEM) showed that Transformational and Transactional leadership styles could positively influence on organizational culture. Laissez-fair leadership has a negative effect on organizational culture. In conclusion, transformational leadership style was recommended to balance all four traits of Denison's organizational culture.

\section{Introduction}

Mapsa Company was established in 1999 as a private company in Iran providing a unique competitive edge in the field of project management consultancy concerning industrial projects. Their mission is to facilitate the precise clients' requirements with the latest use of scientific achievements in management and project control. This company has literally hundreds of highly qualified employees and leaders that face multiple challenges that need to be responded rapidly because these continuous challenges will influence the success of their organization. For instance, markets become unstable, customer needs and desires are changing and information flow is becoming more diverse and complex. The leader's capability to adapt organizational culture in response to these challenges has become a critical success factor for today businesses. Leadership and culture have been recognized as critical concepts associated with organizational effectiveness. An early pioneer in the field of cultural research, Schein (1996), contends that the most important function of a leader is associated with the creation, changing and manipulating of organizational culture. According to Schein (1996) "the unique function of leadership that distinguishes from management is the concern for culture'. The

*Corresponding author. Tel: +989121710924

E-mail addresses: azadeh.khazaneh@yahoo.com (A. Tahvildar Khazaneh) 
type of leadership behavior or style will directly influence organizational environment and culture (Bass, 1985; Barker, 1990). In order to be a successful leader, one must be able to accurately evaluate the organization's culture and assist followers in understanding it well. Scholars in various disciplines have defined these phenomena as the driving forces in the success or failure of an organization (Schein, 2010).

Despite such implicit and explicit linking of leadership and organizational culture in many parts of the organizational theory, little critical research has been devoted to understanding the link between them. Addressing this gap in the literature, this paper provides an evidence of the links between leadership styles and organizational culture. Specifically, the paper addresses the following question: Does leadership styles influence on organizational culture?

\section{Literature Review and Hypotheses}

\subsection{Leadership}

In fact, there is no literally consensus on the definition of leadership. There are several proposals of what a leader should be and do, and various lists of core competencies or traits that leaders should exhibit (Schein, 2010). Researchers have tried to define it in various words but all of them have the same meaning. In fact there is a small difference seem to exist among them. The differences are in the scope of the concept that the authors used. Leadership is the relationship between the leader and followers (Barker, 1990; Lett, 1999). In this research, leadership is defined as a process that places an emphasis on social interaction and relationship that includes influencing others in a certain direction (Gholamzadeh, 2012). For this purpose Full-Range Leadership (FRL) theory was used that comprises leadership dimensions which are highly transformational at one end to highly avoidance at the other end (Avolio \& Bass, 2004). The FRL theory consists of three leadership styles:

\subsubsection{Transformational leadership}

Avolio and Bass (2004) contend that transformational leadership behavior is the ability to impact others toward achievement of extraordinary objectives by changing the follower's belief's, values and requirements. The key aspects of that include the following four elements:

1-Idealized influence (attributed) is referred to the socialized charisma of the leader, where the leader is perceived as being confident and powerful. Idealized influence (behavior) is the leader's charismatic actions that are centers on values, beliefs, and sense of mission. 2-Inspirational motivation is the way leaders energize their followers by viewing the future with optimism, stressing ambitious goals, sharing an idealized vision, and communication to followers that vision is achievable. 3Intellectual simulation is the leader's actions that appeal to follower sense of logic and analysis by challenging followers to think creatively and find solutions to difficult problems. 4-Individualized consideration is the leader's behavior that contributes to follower's satisfaction by advising, supporting, and paying attention to the individual needs of followers, and thus allowing them to develop and self-actualize (Gholamzadeh, 2012; Avolio \& Bass, 2004; Antonakis et al., 2003).

\subsubsection{Transactional leadership}

Transactional leadership is an exchange process based on the fulfillment of contractual obligations and it is typically applied by setting objectives, mentoring, and controlling outcomes (Avolio \& Bass, 2004). The key aspects of that include: 1-Contingent reward, which is the leadership behavior focused on clarifying role and task requirements and providing followers with material or psychological rewards contingent on fulfillment of contractual obligations. 2-Management by exception (active), which refers to the active vigilance of a leader whose goal, is to ensure that standards are met. 
Management by exception (passive), which refers to leaders that only intervene after non-compliance, has occurred or when mistakes have already happened (Gholamzadeh, 2012; Avolio \& Bass, 2004; Antonakis et al., 2003).

\subsubsection{Laissez-faire Leadership}

Laissez-fair or non-transactional leadership represents the absence of a purposeful interaction between the leader and the follower. The leader prevents making directions, abdicates responsibility, and does not implement his/ her authority (Gholamzadeh, 2012; Avolio \& Bass, 2004; Antonakis et al., 2003). According to Block (2003), this leadership is considered as the most passive and ineffective form of leadership.

\subsection{Organizational culture}

Peters and Waterman (1982) defined culture a factor in determining the quality of organizations. According to them, organizational success and excellence rests upon strong and positive cultures. There is no single accepted definition of organizational culture and several models exist to evaluate and measure it (Cameron \& Quinn, 1999). According to Schein (1985), "The pattern of basic assumptions, invented or developed by a given group as it learns to cope with its problems of external adaptation and internal integration and therefore to be taught to new members as the correct way to perceive, think and feel in relation to problems". He define it as symbolic meaning, and underlying beliefs and assumptions which are the deeper levels of culture and are not subject to comparative analysis and are best understood through clinical or ethnographic methods. On the other hand, there are culture researchers who have insisted in the development of systematic approaches to comparative measurement. Similar to Schein, Denison (1990) defined it as "underlying beliefs, values, and assumptions held by members of the organization, and the practices and behaviors that exemplify and reinforce them". He developed a comparative measurement at the level of values and behavioral norms. The Denison organizational culture model is based on four cultural traits that reflect the ability to balance the dynamic tension between the need for stability and the need for flexibility. Each of these broken down into three indexes and describes specific behaviors in business language to make the results relevant and applicable in the organization.

1-Involvement: Building human ability and generating a shared sense of ownership and responsibility throughout the organization.

- Empowerment: Individuals have the authority, initiative, and capability to manage their own work.

- Team Orientation: Value is placed on working cooperatively toward common goals.

- Capability Development: The organization continually invests in the development of employee's skills.

2-Consistency: Defining the values and systems that are the basis of the culture.

- Core values: Members of the organization share a set of values.

- Agreement: Members of the organization are capable of reaching agreement on critical issues.

- Coordination and Integration: Various functions and units of the organization are able to work together well to achieve common objectives.

3-Adaptability: Translating the demands of the external environment into some possible actions.

- Creating change: The organization is capable of creating adaptive ways to meet changing needs.

- Customer focus: The organization understands and reacts to their customers and anticipates their future needs. 
- Organizational learning: The organization receives, translates, and interprets signals from the environment into opportunities.

4-Mission: Defining a meaningful long-term direction for the organization.

- Strategic direction and intent: Clear strategic intentions.

- Goals and Objectives: A clear set of goals and objectives can be linked to the mission, vision, and strategy.

- Vision: The organization has a shared view of a desired future state (Denison, 1990;

- Denison \& Mishra, 1995; Gordon \& DiTomaso, 1992; Sorensen, 2002; Denison, 2014).

In terms of these traits, the Denison organizational culture survey (DOCS) answers to four key questions about the organization (Denison, 2006): 1-Are employees aligned, engaged and capable? 2Does the organization has the values, systems and processes in place to execute? 3-Do employees listen to the marketplace? 4-Does the organization knows where it is going? Dennison's findings suggested that success of an organization is related to certain organizational culture elements.

\subsection{Leadership and Culture}

Many researchers recommend that the style of a leader could influence on organizational culture. They report that leader is the creator of the organizational culture, which reflects his/ her unique values and beliefs (Bass, 1998; Schein, 2010). Bass (1998) contends that the culture influences on leadership as much as leadership affects culture. If the culture has increased autonomy within the lower levels of the organization, then the leader will have to diminish personal power.

Leaders can transform and change the culture (Lewis, 1996). According to Schein (1985), "the only thing of real importance that leaders do is to create and manage culture". The results of most studies indicated that transformational leadership has positive impacts on the organizational culture (Lewis, 1996; Kramer, 1990; McClure et al., 1983; Deluga, 1988). Transformational leadership, changes the organizational culture but the transactional leadership works within the culture as it exists (Bass, 1998). Furthermore, it provides a broader perspective and takes into account the complexity of the culture (Mullins, 2007). According to Deal and Peterson (1993), creating, changing, and shaping culture are all roles of effective leaders. Schein (2010) contends that whenever the elements of the culture become mismatched to its environment and dysfunctional, the leader can make changes.

Bennis and Nanus (1985), determined the qualities of a successful leader. According to them successful leader is a transformational one who creates and communicates a vision to construct a successful organizational culture which promotes creativity, trust, two-way communication, mutual decision-making, and personnel development.

\subsection{Research conceptual model}

According to these explanations, it will be logical to relate leadership styles of managers to the organizational culture.

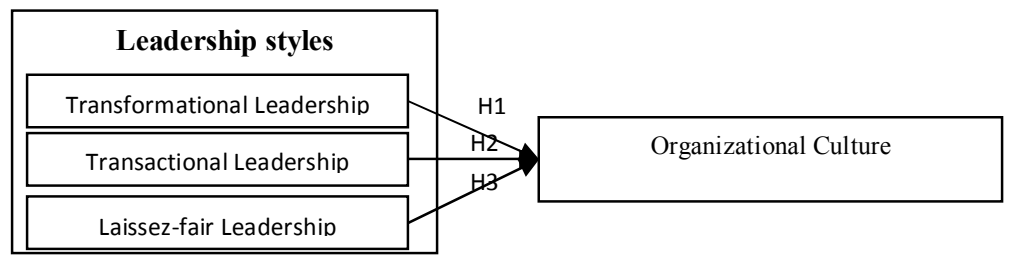

Fig.1. Research Conceptual Model 


\subsection{Research Hypotheses}

In the present study the following hypotheses are tested:

$\mathrm{H}_{1}$. Transformational Leadership is positively associated with Organizational culture.

$\mathrm{H}_{2}$. Transactional leadership is positively associated with Organizational culture.

$\mathrm{H}_{3}$. Laissez-fair leadership is negatively associated with Organizational culture.

\section{Research methodology}

The purpose of this research is to find an answer to the following question: how do leadership styles affect their organizational culture?

This survey is conducted on 93 employees who were working in Mapsa Company in October 2012. The sampling criteria were adults including, 38 females and 55 males. The participants ages ranging from 20 to 60; 67 percent were married; 89 percent had permanent contracts; 32 percent had less than one year of work experience in Mapsa, and 94 percent were above diploma and college graduated.

To test the proposed model, a quantitative survey method was used. Sample size was computed 93 through Cochran's sample size formula for a population amount of 120 employees. The data were collected through handing in the questionnaires to employees. Two types of questionnaires were used; Leadership styles and organizational culture. The questionnaire also includes six direct questions on socio-demographic characteristics. The measure of leadership style was adopted from Bass and Avolio (1995) Full range leadership model. The 20 items were used to measure four factors of transformational leadership ( $\alpha=0.95), 12$ items measured two factors of transactional leadership ( $\alpha=0.76)$, and 4 items were used to measure two factors of laissez-fair leadership $(\alpha=0.70)$. The measure of organizational culture was adopted from Denison organizational culture (2006) model. The 15 items were used to measure three factors of Involvement $(\alpha=0.82), 15$ items measured three factors of Consistency ( $\alpha=0.84$ ), 14 items measured three factors of Adaptability ( $\alpha=0.78$ ), and 15 items measured three factors of Mission $(\alpha=0.91)$.

In order to examine the content validity of questionnaires, it was examined by field experts and in order to determine its reliability and construct validity a pilot study of the instruments were done and corrections were made based upon the feedback received.

To test the conceptual model and hypotheses, descriptive analysis, confirmatory factor analysis (CFA), and structural equation modeling (SEM) two-step approach were employed using SPSS 19 and Amos 19. Multiple criteria were used in the present study to evaluate the goodness of model fit including the $x^{2}$, the comparative fit index (CFI), the root mean square error of approximation (RMSEA), and standardized root mean square residual (SRMR) indices.

\section{Results}

The test of the measurement model indicated an adequate fit to the data: $x^{2}=68.81, p=0.021$, $x^{2} / d f=1.46, \quad \mathrm{RMSEA}=0.07, \mathrm{SRMR}=0.06, \mathrm{CFI}=0.97$. The high standardized loading in the measurement model revealed that latent variables-TFL, TRL, LF, OC- have good construct validities.

Before estimating the hypothesized model, the multivariate normality assumption of SEM was evaluated in AMOS. The skewness statistics for tested constructs and the critical z-value was obtained. Since these values did not exceed a critical value of \pm 1.96 ; so, the result passed the data normality test. 
The hypothesized structural model demonstrates a good fit to the data: $x^{2}=68.81, p=0.021$, $x^{2} / d f=1.46, \mathrm{RMSEA}=0.07, \mathrm{SRMR}=0.06, \mathrm{CFI}=0.97$. The results showed that all standardized path coefficients were statistically significant.

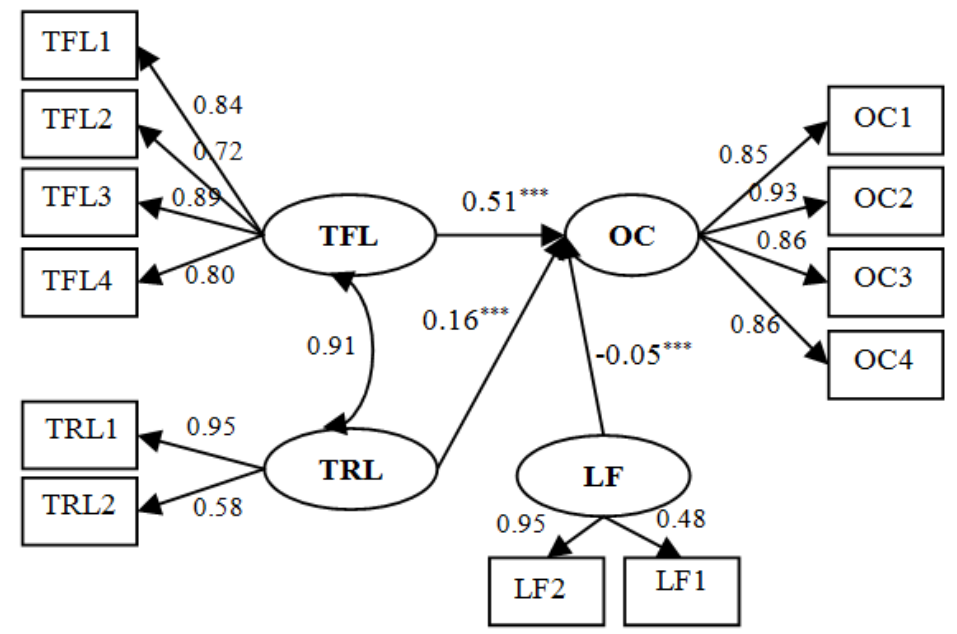

Fig.2. Results of the retained (simplified) model

${ }^{* * *} \mathrm{p}<0.001$

As presented in Fig. 2, consistent with the literature, transformational leadership was found to covariate with transactional leadership, $\beta=0.91, p<0.001$. An effective leader could demonstrate both transformational and transactional leadership styles.

$\mathrm{H}_{1}, \mathrm{H}_{2}$, and $\mathrm{H}_{3}$ proposed the direct effect of Transformational, Transactional and Laissez-fair leadership on Organizational culture. As indicated in Fig. 2, all three hypotheses were supported; transformational leadership had a large positive effect on organizational culture, $\beta=0.51, p<0.001$, and transactional leadership was found to have a less positive effect on Organizational culture, $\beta=0.16, p<0.001$. In contrast, Laissez-fair leadership was found to have a negative effect on organizational culture, $\beta=-0.05, p<0.001$.

Fig. 3 summarizes percentage of the four cultural traits and their respective indexes for the Mapsa Company. The results showed that Adaptability appears to be the strongest cultural trait followed by mission. On the contrary, consistency appears to be the weakest cultural trait. The indexes: 1Agreement, 2-Coordination and Integration 3-Capability development obtained the lowest percentage.

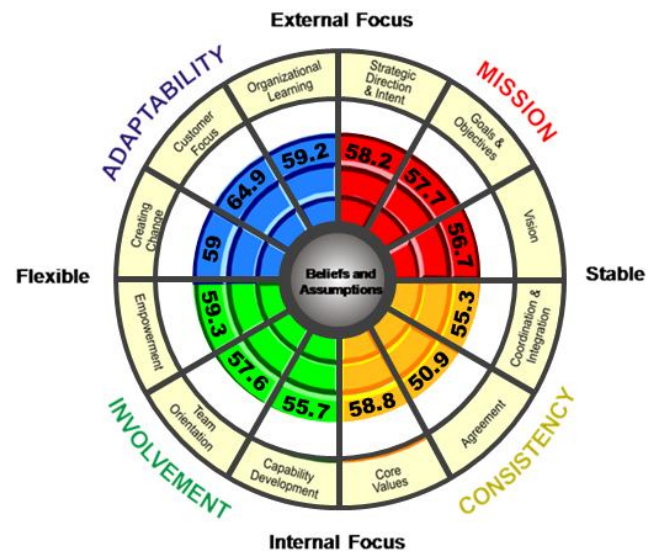

Fig. 3. The Circumplex Report of Denison model for Mapsa Company 


\section{Discussion and conclusion}

Schein (1996) contends that understanding the relationship that exists between the leader and the culture is a mechanism for understanding the functioning of the organization. He claims that leadership and culture are two sides of the same coin and neither can be understood by itself. Leader have the ability to influence culture, he can transform and change a culture (Lewis, 1996; Bass, 1998; Deal \& Peterson, 1993). The current study represents how organizational culture is influenced by leadership styles.

The results revealed that Transformational leadership positively influences Organizational Culture. Leaders shape culture by sharing corporate vision, policy deployment, influencing information flow, and stimulating involvement and teamwork (Peters \& Waterman, 1982). The findings are in line with previous literature on the positive relationship between Transformational leadership and Organizational Culture (Bass \& Avolio, 1994; Bennis \& Nanus, 1985; Kramer, 1990; McClure et al., 1983; Bass, 1985; Coeling \& Wilcox, 1988; Dunham, 2000).

Furthermore, Transactional leadership in the current study demonstrated a positive effect on Organizational Culture. When managers over reliance on rewards and punishment to exert influence and mainly focus on economic and instrumental transactions in treating employees, as well as when they exert more control, actually they work within the culture as it exists (Bass, 1985). They accept and use the rituals, stories, and role models belonging to the organizational culture to communicate their values (Bass, 1985). This concurs with the findings from previous studies that, although Transactional leadership can be effective or even necessary but is less likely to generate and change the organizational culture compared to Transformational leadership (Bass, 1985; Avolio \& Bass, 2004).

In contrast, the results of the present study disclosed that Laissez-fair leadership style was negatively associated with Organizational Culture; in other words, because of the absence of purposeful interaction between leader and employees, and also the avoidance to making decision, these leaders demonstrate negative and less effect on organizational culture. The findings are in line with previous literature on the negative relationship between Laissez-fair leadership and Organizational Culture (Block, 2003; Cassida \& Genevieve, 2008).

Moreover, the Circumplex report as showed in Fig. 3, gives an overview of what Mapsa company culture looks like as a whole and helps to determine overall pattern of strengths and weaknesses. The current study demonstrated that Mapsa Company seems to be flexible. They can change quickly in response to their environment and is successful at being innovative and satisfying their customers. Moreover, has external focus, they have eye towards the market and are able to adapt and change in response to what they see. They have ability to grow as they meet the current and future needs of the marketplace. In addition, they have top-down bottom-up alignment which represented by the balance between the Mission (top-down) and employee Involvement (bottom-up).

The high Adaptability scores demonstrate that external perspectives are valued. High score in Customer Focus indicates that customer understanding and responsiveness is paramount. The balance between Mission and Adaptability suggest that strategies and goals are based on informed consideration and understanding of the marketplace. The balance between Involvement and Adaptability suggest that risk taking and innovation are encouraged and there is no fear of blame. The balance between Involvement and Mission trait show that information flows freely in all directions.

High goals and low overall Consistency with the high flexibility side suggest the organizations ideas are plentiful but follow through is rare. Low Coordination and Integration suggest that business units and functions may be pursuing their own 'self' interests rather than the interest of the whole company; 
this idea is strengthened when we see the high scores in Team Orientation next to the low Coordination and Integration. This further suggests that relationships are developed within teams, not across the organization.

Findings of the present study showed that effective leadership such as Transformational leadership makes a large positive impact on Organizational Culture, whereas Transactional and Laissez-fair leadership does not. In addition, successful organizations have strengths across all four traits of the Denison model (Denison, 2006).

The Transformational leadership style should thereby be recommended rather than the Transactional leadership style. Besides, while overall balance in all four traits is the goal, leaders of this company can focus on 1-Agreement, 2-Coordination and Integration 3-Capability development to build its strength as evidenced by the current study.

Mapsa Transformational leaders need to develop the skills that enable them to alter aspects of their Organizational Culture (Brown, 1992). For changing and improving the Agreement and Coordination and Integration indexes of the Consistency trait they can:

- Share goals and objectives throughout the organization so that employees at every level understand the key areas,

- Conduct a decision-making workshop to explore the types of decisions made and how they will be addressed,

- Identify the behaviors and practices that will guide team interactions,

- Select employees who fit in with the cultural ideals and assumptions,

- Use a variety of interpersonal communication and personality assessment tools to highlight differences among individual styles and how to leverage those differences in the workplace,

- Conduct a fast feedback workshop to assess how well they are meeting their needs and how well they are meeting other's needs,

- Identify the behaviors and practices that will guide organizational cross-functional team interactions,

- Create an interactive forum for employees to share ideas and discuss how their work impacts the organizational processes,

- Conduct annual 360 assessments that provide feedback to leaders and managers from their direct reports, peers and boss.

Besides, for changing and improving the Capability Development index of the Involvement trait they can:

- Evaluate coaching needs and interventions that develop the individual's capabilities,

- Implement mentoring and coaching programs particularly to high-potential employees,

- Present employees with the opportunity to work with colleagues from other parts of the organization,

- Promote employees whom are capable of taking on greater responsibility,

- Conduct leading change, training seminars,

- Encourage professional development so that the employee is aware of industry trends and developments.

Thus, Transformational leaders need to have a clear action plan which help us build accountability into changing and improving process and they need to review the change progress at regular intervals to align their culture change and leadership development. 


\section{Limitation and future research}

One possible limitation was generalizability of the model. It would be recommended to replicate this study from one single company to in one particular industry. A second limitation was the common source measurement; that is, the data were collected only from employee's perspective. To provide a more comprehensive understanding of how leadership styles influence organizational culture, leaders should be incorporated. The third limitation is the two specific models of leadership styles and OC used in this research to assess the relationships between them. Future research can be focused on some other parameters of OC and alternative measurement tools. The forth limitation was associated with the range of samples, In future research, a wider range of samples from different kinds of organizations across various industries should be used to test the proposed model and generalize the findings. A fifth limitation was the lack of moderating or mediating factors influencing OC, In future research, it is also important to explore other variables that may be associated with the differences in leadership styles and organizational culture.

\section{References}

Antonakis, J., Avolio, B.J., \& Sivasubramaniam, N.(2003). Context and leadership: An examination of the nine-factor full range leadership theory using multifactor leadership questionnaire. The Leadership Quarterly, 14, 261-295.

Avolio, B. \& Bass, B.(1995). Individual consideration viewed at multiple levels of analysis: A multilevel framework for examining the diffusion of transformational leadership. Leadership Quarterly, 6, 199-218.

Avolio, B.J. and Bass, B.M.(2004). Multifactor Leadership Questionnaire: Manual and Sampler Set. 3rd ed., Redwood City, CA: Mind Garden.

Barker, A.(1990). Transformational nursing leadership: A vision for the future. Baltimore: Williams \& Wilkins,

Bass, B.(1985). Leadership and performance beyond expectations. New York: Free Press.

Bass, B.M. \& Avolio, B.J.(1994). Improving Organizational Effectiveness through Transformational Leadership. Newbury Park, CA: Sage, 1994.

Bass, B.(1998). Transformational leadership: Industry, military, and education. Journal of Leadership Studies, 5, 169.

Bennis, W. \& Nanus, B.(1985). Leaders, New York: Harper and Row.

Blake, R. \& Mouton, J.(1989). Executive achievement: Making it to the top. New York: McGrawHill.

Block, L.(2003). The leadership-culture connection: an exploratory investigation. Leadership\& Organization Development Journal, 24 (5/6), 318-334.

Brown, A.(1992). Organizational Culture: The Key to Effective Leadership and Organizational Development. Leadership and Organizational Development Journal, 13(2), 3-6.

Cassida, J., \& Pinto-Zipp, Genevieve(2008). Leadership-Organizational Culture Relationship in Nursing Units of Acute Care Hospitals, Nursing Economics, 26.

Cameron, K. S., \& Quinn, R. E.(1999). Diagnosing and changing organizational culture. Reading, MA: Addison-Wesley.

Coeling, H. \& Wilcox, J.(1988). Understanding organizational culture. Journal of Nursing Administration, 18, 16-23.

Deal, T \& Peterson, K.(1993). Technical and symbolic Aspects of school improvements, Madison, WI: University of Wisconsin-Madison Center for Research, National Center for Effective Schools.

Deluga, R.(1988). Relationship of transformational and transactional leadership with employee influencing strategies. Group \& Organizational Studies, 13, 456-467. 
Denison, D.(1990). Corporate culture and organizational effectiveness. New York: John Riley \& Sons.

Denison, D R., \& Mishra, Aneil K.(1995). Toward a Theory of Organizational Culture and Effectiveness Organization Science. Mar/Apr, 6(2), 204-223,

Denison, D.R.(2006). The Denison organizational culture model, Retrieved June 9, 2013, from http://dsa.umich.edu/files/dsa/Getting\%2BStarted\%2BGuide.pdf.

Dunham, T.(2000). Nurse executive transformational leadership found in participative organizations. Journal of Nursing Administration, 30, 241-50.

Gholamzadeh, D.(2012), Leadership. Tehran: Termeh.

Gordon, G. G.,\& DiTomaso, N.(1992). Predicting corporate performance from organizational culture. Journal of Management Studies, 29, 783-798.

Kotter, J. P., \& Heskett, J. L.(1992). Corporate culture and performance. New York: The Free Press.

Kramer, M.(1990). The magnet hospitals excellence revisited, Nursing Administration, 20, 35-44.

Lett, M.(1999). The need for leadership. Contemporary Nurse. 8, 136-41.

Lewis, D.(1996). The organizational culture saga: A critical review of the literature. Leadership \& Organization Development Journal, 17,12-19.

McClure, M., Pulin, M., Sovie, M., \& Wandelt, M.(1983). Magnet hospitals attrition and retention of professional nurses. American Nurses Association Publication, Kansas City: American Nurses' Association.

Mullins, L.J.(2007). Management and Organizational Behavior. Prentice Hall.

Peters, T. \& Waterman, R.(1982). In search of excellence. New York: Harper and Row.

Schein, E.(2010). Organizational culture and leadership. San Francisco: Jossey-Bass.

Sorensen, J. B.(2002). The Strength of Corporate Culture and the Reliability of Firm Performance. Administrative Science Quarterly, 47, 70-91. 